\title{
A suspended-particle rosette multi-sampler for discrete biogeochemical sampling in low-particle-density waters
}

\author{
J.A. Breier ${ }^{\mathrm{a}, *}$, C.G. Rauch ${ }^{\mathrm{a}}$, K. McCartney ${ }^{\mathrm{b}}$, B.M. Toner ${ }^{\mathrm{c}}$, S.C. Fakra ${ }^{\mathrm{d}}$, S.N. White ${ }^{\mathrm{a}}$, C.R. German ${ }^{\mathrm{a}}$ \\ a Woods Hole Oceanographic Institution, Woods Hole, MA 02543, USA \\ ${ }^{\mathrm{b}}$ Massachusetts Institute of Technology, Cambridge, MA 02139, USA \\ ${ }^{\mathrm{c}}$ University of Minnesota - Twin Cities, St. Paul, MI 55108, USA \\ d Lawrence Berkeley National Lab, Berkeley, CA 94720, USA
}

Keywords:

Deep-sea

Hydrothermal vents

Geochemistry

Suspended particles

Instrumentation

Remotely operated vehicle

\begin{abstract}
A B S T R A C T
To enable detailed investigations of early stage hydrothermal plume formation and abiotic and biotic plume processes we developed a new oceanographic tool. The Suspended Particulate Rosette sampling system has been designed to collect geochemical and microbial samples from the rising portion of deep-sea hydrothermal plumes. It can be deployed on a remotely operated vehicle for sampling rising plumes, on a wire-deployed water rosette for spatially discrete sampling of non-buoyant hydrothermal plumes, or on a fixed mooring in a hydrothermal vent field for time series sampling. It has performed successfully during both its first mooring deployment at the East Pacific Rise and its first remotely-operated vehicle deployments along the Mid-Atlantic Ridge. It is currently capable of rapidly filtering 24 discrete large-watervolume samples (30-100 L per sample) for suspended particles during a single deployment (e.g. $>90 \mathrm{~L}$ per sample at $4-7 \mathrm{~L}$ per minute through $1 \mu \mathrm{m}$ pore diameter polycarbonate filters). The Suspended Particulate Rosette sampler has been designed with a long-term goal of seafloor observatory deployments, where it can be used to collect samples in response to tectonic or other events. It is compatible with in situ optical sensors, such as laser Raman or visible reflectance spectroscopy systems, enabling in situ particle analysis immediately after sample collection and before the particles alter or degrade.
\end{abstract}

\section{Introduction}

Suspended particulate material is ubiquitous throughout the hydrosphere. In its broadest definition it is composed of living and non-living material and spans a range of particle sizes, compositions, and concentrations. The formation, transport, dissolution, and burial of particulate material are fundamental to biogeochemical cycles (Anderson et al., 2003). The distribution and transport of the biotic components of suspended particles
- larvae, plankton, microbes, and viruses - are equally important in understanding aquatic ecosystems. Niskin bottles, in situ filtering pelagic pumps, and a variety of specialized apparatus have served most suspended particle sampling needs. However, in deep-sea hydrothermal plumes, we are undertaking new geochemical and microbial research in environments that require spatially and temporally precise sampling.

To accomplish this, we have developed a novel Suspended Particulate Rosette (SUPR) multi-sampler that can be deployed either on a mooring for unattended time series sample collection or on a remotely operated vehicle (ROV) to enable sampling tasks such as vertical-profiling of rising hydrothermal plumes. The SUPR sampler is 

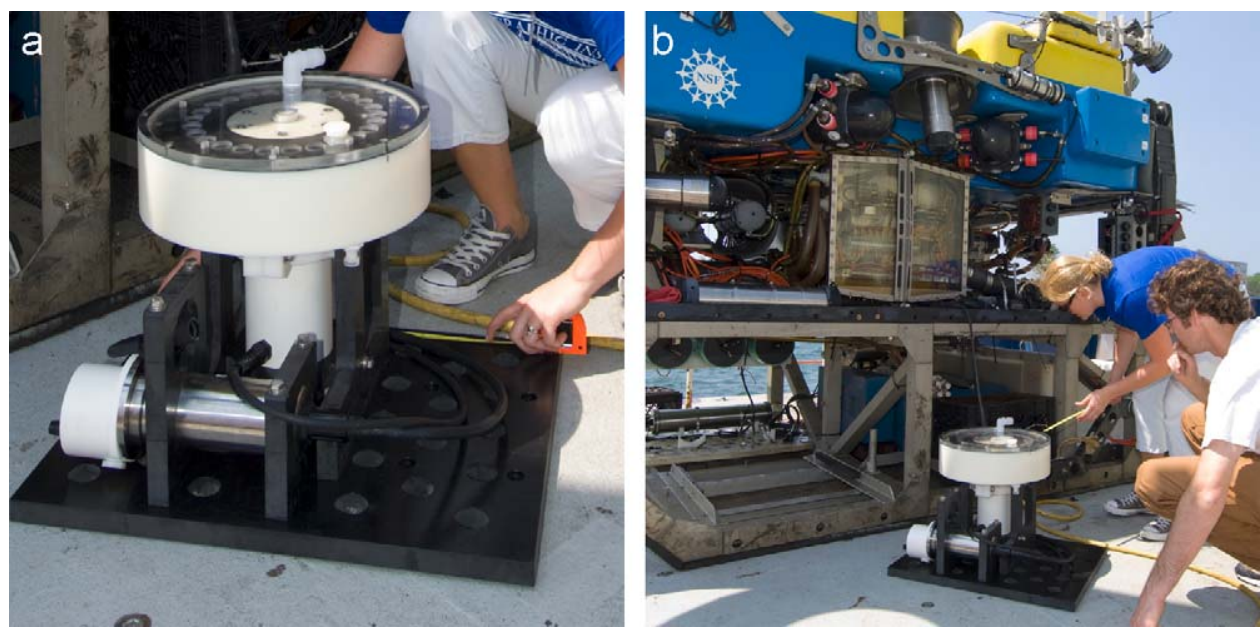

Fig. 1. The SUPR sampler is a WHOI designed and built, optical-sensor compatible, multi-sample filtering head interfaced to a McLane Research Laboratories high-flowrate pumping system. When configured for ROV deployments the SUPR system (a) is compact enough to fit into any science payload position on the ROV Jason (b).

currently capable of rapidly filtering 24 discrete largewater-volume samples $(30-100 \mathrm{~L}$ per sample at $4-7 \mathrm{~L}$ $\mathrm{min}^{-1}$ through $25-47 \mathrm{~mm}$ diameter filters) for suspended particles during a single deployment. The ROV version weighs $7 \mathrm{~kg}$ in water and occupies a volume $<0.1 \mathrm{~m}^{3}$ (Fig. 1). It is designed to host in situ optical sensors, such as a dedicated laser Raman spectroscopy system, to enable in situ particle analysis. In this paper, we discuss the scientific need for the SUPR-sampler, the sampler design, and results from the first two at-sea deployments: a) moored on the East Pacific Rise (EPR) in 2007, and b) ROVdeployed on the Mid-Atlantic Ridge (MAR) in 2008.

\section{Scientific background}

Processes in hydrothermal plumes alter the gross chemical fluxes from hydrothermal vents to the oceans. Two general processes have been identified: Process I) coprecipitation of Fe and other chalcophile elements to form polymetallic sulfide phases immediately when vent fluids enter the ocean (i.e. a "quenching" effect); and Process II) co-precipitation of trace elements with, and sorption of dissolved metals onto, freshly-formed Fe oxyhydroxide phases as the reduced vent fluids mix with more oxidizing ambient ocean waters (Feely et al., 1987; Lilley et al., 1995; German and Von Damn, 2003). While much of the chemical flux from Process $I$ is deposited on the seafloor as metaliferous sediments, Process II results in the generation of a low-density particle floc that can be dispersed many kilometers through the water column. Also during Process II, seawater nutrients and trace elements (e.g. P, As, Cr, and V) are scavenged by the highly reactive $\mathrm{Fe}$ - and $\mathrm{Mn}$-rich plume particles (Mottl and Mcconachy, 1990; Metz and Trefry, 2000). It may take less than 10,000 years for the entire ocean to pass through the plumes of Earth's deep-sea vents (Feely et al., 1991; Kadko, 1993; Elderfield and Schultz, 1996). This is rapid in geologic terms; therefore, the processes that occur within hydrothermal plumes may have a direct effect on global seawater chemistry (Kadko et al., 1995).

In addition to geochemical transformations, Fe and Mn oxidation reactions are thought to be important energy sources for chemosynthetic microbial communities at and below the seafloor (Edwards et al., 2003; Bach et al., 2006). Microbial processes may also be important in hydrothermal plumes (e.g. Cowen and German, 2003), affecting oxidation rates and the ultimate fate of hydrothermal plume particles. Estimates of the chemical energy available within hydrothermal plumes show that a variety of chemosynthetic metabolic pathways are possible (McCollom and Shock, 1997). Deming and Baross (1993) reported elevated particulate DNA and cell concentrations in rising vent fluids. Several studies have shown evidence of microbial activity within neutrally buoyant hydrothermal plumes based on $\mathrm{Mn}$ and $\mathrm{CH}_{4}$ oxidation and biomass production (Cowen et al., 1986; De Angelis et al., 1993; O'Brien et al., 1998; Dick et al., 2006). It is unknown whether such microbial communities are opportunistic or endemic, and if endemic how they persist in such a physically dynamic setting.

It should be stressed that most of our understanding of hydrothermal plume processes has come from sampling fluids near vent orifices and particles from neutrally buoyant plumes, typically $100-200 \mathrm{~m}$ above the seafloor. Because of the technical challenges, comparatively few samples have been collected from the buoyant (rising) portion of hydrothermal plumes, where most particles initially form and are most reactive. To develop a better understanding of biotic and abiotic plume processes, we have developed a new tool that can systematically sample particles from discrete locations within these rising and laterally spreading hydrothermal plumes.

\subsection{Sampling needs}

To systematically sample rising hydrothermal plumes, sample collection must be rapid enough that an adequate 
sampling plan can be carried out within a single ROV dive. Samples must be collected over a wide range of suspended particle concentrations; because hydrothermal fluids are diluted by a factor of $10^{4}$ by the time the vent fluid/ seawater mixture reaches the level of a dispersing plume (Lupton, 1995). Samples must also be collected across a range of particle sizes. Excluding plankton, the largest hydrothermal particles are on the order of $10 \mathrm{~s}$ of microns, while the smallest particles are at the nano-scale (although the currently accepted, operationally-defined limit is $0.2 \mu \mathrm{m}$ ). For microbial analysis, cells as small as $0.2 \mu \mathrm{m}$ are significant and must be collected. For geochemical analysis, collecting $\geq 1 \mu \mathrm{m}$ sized particles and larger is currently the most pragmatic option because it allows sufficient material for a variety of analyses. Evidence suggests that in hydrothermal plumes most of the particle mass is associated with larger particles (Bennett, pers. comm., unpublished data), though a better quantification of this for rising plumes is an excellent application for our SUPR-sampler.

In addition to the sampling requirements listed above, the sampler design must be compatible with both tracemetal and microbial cleanliness practices and standards. The sampler should be depth rated to at least $5500 \mathrm{~m}$, allowing access to all currently known deep-sea hydrothermal vents, such as the recently discovered Ula Nui vent field on the abyssal flanks of Loihi seamount at $5000 \mathrm{~m}$ (Davis et al., 2007). When operated on an ROV, it should be small and compact, and when deployed autonomously, it should have sufficient battery capacity to filter as much as $2400 \mathrm{~L}$ total for up to a 12 -month period. For quantitative data reduction, it must record the water volumes filtered for each sample. Finally, since our long-term goal is to perform in situ particle analysis using optical techniques, such as laser Raman and visible reflectance spectroscopies (Breier et al., 2009), we require an optically compatible particulate sampler.

\subsection{Existing particulate samplers}

The time-tested particulate multi-sampler is a set of Niskin or GO-FLO ${ }^{\circledR}$ bottles combined with surface filtration. Some examples of this type of sampling include the following. On the Endeavor Segment of the Juan de Fuca Ridge, Straube et al. (1990) collected 25 whole-water samples from the rising buoyant plume using 1.5- and 5-L GO-FLO ${ }^{\circledR}$ bottles deployed on the Alvin submersible. On the Cleft Segment of the Juan de Fuca Ridge during Alvin dives on January 1990, Cowen et al. (1990) collected whole-water samples (1-10 $\mathrm{m}$ above vents) using 1.7 - and 10 -L Niskin bottles in the lower portion of the plumes. The same sampling approach was also used at TAG on the MAR (Edmond et al., 1990; Rudnicki and Elderfield, 1993). There have also been instances where the upper portions of buoyant plumes were sampled by vertical CTD-rosette and wire-deployed, stand-alone pump casts (e.g., Bennett et al., 2008; Edmonds and German, 2004; G. Wheat and J. Resing, pers. comm.), but this method is highly dependent on surface and subsurface conditions and has been neither systematic nor reliable. There are three major drawbacks to the bottle approach: i) sample size is limited by bottle volume, ii) sample payload is limited by collecting wholewater samples and iii) samples can be biased by particle adherence to the bottle walls. Mitra et al. (1994) describes the bias that can occur when filtering particles from water bottles.

Sampling by in situ filtration is a good solution to the disadvantages of whole-water samplers. However, there is a tradeoff; whole-water samplers collect a sample almost instantaneously, whereas in situ filtration may take several minutes to collect a sample from a comparable water volume. The time-scales of the processes involved and science needs will dictate whether a water sampling or in situ filtration approach to sample collection is more appropriate. For our applications, the advantages of in situ filtration out weigh the tradeoff in sampling speed. Several in situ filtration approaches to particle and fluid multi-sampling have been developed for specific scientific applications. We considered four existing samplers during the SUPR design process: the Continuous Plankton Recorder (CPR), the Butterfield et al. (2004) Hydrothermal Fluid and Particulate Sampler, the McLane Water Transfer System (WTS) series multi-samplers, and the Sholkovitz et al. (2001) Buoy-Mounted Aerosol Sampler.

The CPR is a towed device that has been used to sample plankton in the surface ocean for decades (Hardy, 1939). It collects plankton onto a spool of mesh that is continuously wound through the device by a propeller driven mechanism. While a pumped, discrete-sample adaptation of the CPR design could be a very compact device, ensuring sample integrity would require a relatively complex design. In addition, opportunities for in situ optical analysis would be limited to one instance immediately after collection.

The Hydrothermal Fluid and Particulate Sampler (HFPS) was developed by Butterfield et al. (2004) for controlled sampling of diffuse hydrothermal fluid at the seafloor by ROV. It can be configured to collect a combination of fluid (filtered or unfiltered), particulate, and gas-tight samples. It continuously measures temperature, just within the inlet and further along the intake tube, to ensure that samples are actually diffuse hydrothermal discharge. It uses a McLane dual multi-port valve to draw water through different sampling ports. Filtered samples are collected on individual $47 \mathrm{~mm}$ diameter filters. Fluid samples are limited to $800 \mathrm{~mL}$, and filtration can take 10 to $15 \mathrm{~min}$ to complete (Huber et al., 2003).

Like the HFPS, the McLane WTS series samplers also use a similar dual multi-port valve to draw water $(<10 \mathrm{~L})$ through individual, typically $47 \mathrm{~mm}$ diameter, filters (e.g. Rendigs and Bothner, 2004). This general design has been adapted to a variety of applications with similar sampling needs, including seafloor microbial sampling at hydrothermal vents (Taylor et al., 2006). Both the HFPS and the McLane WTS systems are intended for relatively small volume samples where minimizing the collection time is not critical. The design of the valve head limits the diameter of the flow path and consequently, the sampling flow rate. In addition, the filter holders do not allow for optical access to a collected sample and the fact that the holders are separate makes interfacing them to an optical 
instrument problematic. Other than the filtering apparatus, several of the McLane components found in these systems (e.g. the stepper motor, controller, and pump) met our requirements with only minor modifications and were used in the SUPR sampler prototype.

The general arrangement of our multi-sample filtering head is based, primarily, on the WHOI Buoy-Mounted Aerosol Sampler, which collects 24 aerosol samples onto filters arranged in a circle (a filter rosette) (Sholkovitz et al., 2001). In this design, one position is for sample collection, and filters are rotated into place as necessary. The flow path is straight through the filter. Another position is available for a sensor for analyzing the $\mathrm{Fe}$ content of the aerosols (e.g., visible reflectance or XRF). This arrangement maximizes the cross-sectional area of the flow path, and the circular pattern of the filter rosette simplifies interfacing with an analysis system. Since the aerosol sampler is not wetted, the filters can be contained in a single, common enclosure and still ensure sample integrity. In this arrangement leaving the samples uncovered provides the optical access necessary for the Fe sensor (also in the same enclosure). However, in submerged applications, samples collected in a single, flooded, enclosure would resuspend, cross contaminate, and compromise sample integrity. However, enclosing each sample individually makes optical access more difficult. Meeting these two design requirements ensuring sample integrity and allowing optical access to the samples - resulted in the SUPR filtering head design discussed in the following sections. In addition to meeting the requirements discussed above, the SUPR design permits: i) collection of sequential or simultaneous replicate particulate sample pairs for complementary geochemical and microbial analysis, and ii) multi-stage filtering to collect separate particle sizeclasses simultaneously.

\section{The suspended particulate rosette (SUPR) sampler}

\subsection{Description}

The SUPR sampler consists of a custom filtering head capable of collecting 24 discrete samples (Fig. 2, Table 1). The design is novel in that it collects multiple samples in a way that is easy to process upon recovery, allows multistage and replicate filtering, and is compatible with in situ optical analysis (patent pending). It also allows a large diameter flow path so that the filters are the limiting factor determining flow rates. The filtering head consists of a housing and filter rosette (Fig. 3).

For ROV deployments, a hose extension and PVC sampling wand are attached to the inlet for positioning with the ROV manipulator. The housing has two outlets. When samples are collected sequentially, only one outlet is used and the other is plugged. When true simultaneous replicate samples are collected, the two outlets are joined at a common union. The prototype housing was fabricated from nylon, with an acrylic cover, and Viton ${ }^{\circledR}$ rubber gaskets. The housing has planned locations for an optical instrument port and a dosing port for introducing stains and reagents, as required for future joint microbial/ geochemical investigations.

The filter rosette consists of a sequence of plates that create separate containments and flow paths for each sample (Fig. 3). For each of the 24 sample locations (plus the purge port) in the filter rosette there is an inlet, a simple closure, a lateral offset, a stack of two filter stages, a

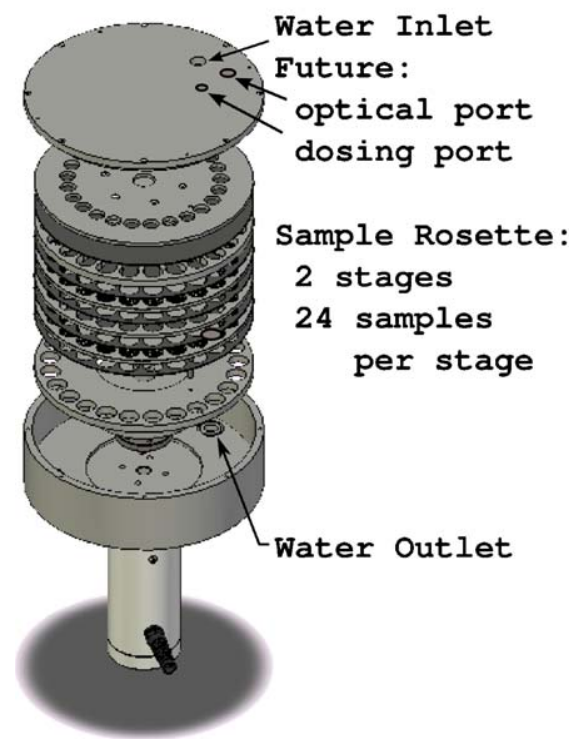

b

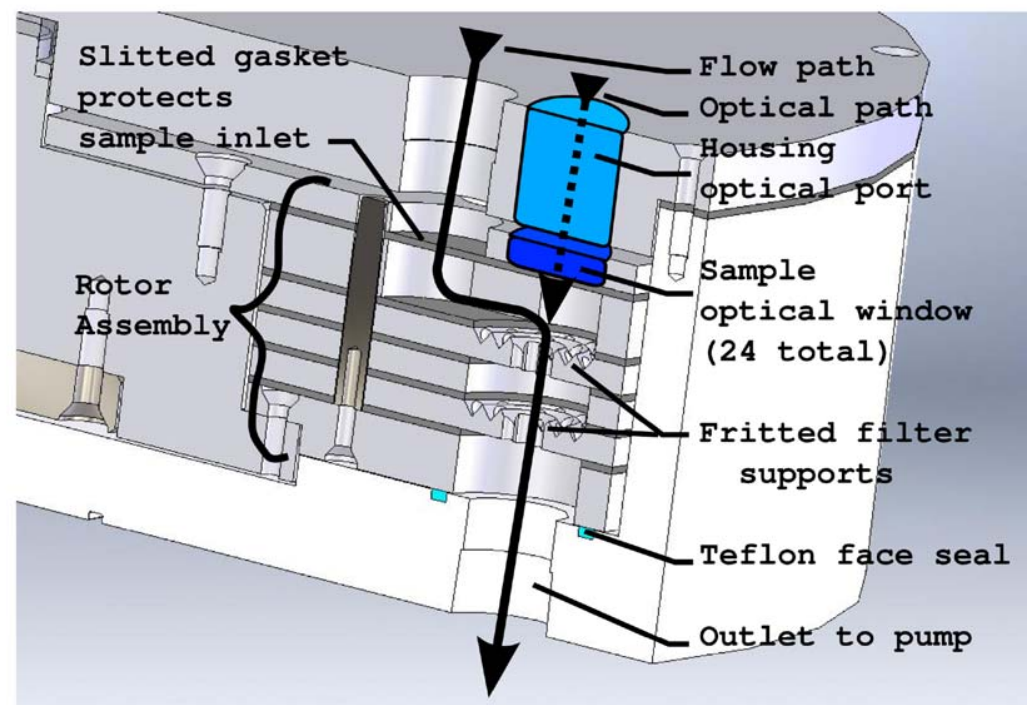

Fig. 2. (a) The SUPR sampling head contains a filter rosette, with 24 filter sample locations, driven by a stepper motor. The water inlet and outlets, and future optical sensor and dosing ports, are stationary. A face seal between the water outlet and the active filter seals the flowpath. (b) A cross section of the SUPR sampler head shows the offset flow path, which provides optical access to the filtered samples. The current prototype has a clear acrylic housing cover and a clear polycarbonate rosette top plate, which allows collection to be monitored in real time via video-link during ROV operations. 
Table 1

SUPR sampler specifications.

\begin{tabular}{|c|c|}
\hline \multicolumn{2}{|l|}{ Functional and physical } \\
\hline Samples & up to 24 \\
\hline Sequential filtration & up to 2 levels \\
\hline Filter pore size & $0.2 \mu \mathrm{m}$ and greater \\
\hline Filter diameter & $25-47 \mathrm{~mm}$ \\
\hline Depth rating & $\begin{array}{l}5000 \mathrm{~m} \text { (autonomous) } \\
5500 \mathrm{~m} \text { (ROV) }\end{array}$ \\
\hline Weights & $60 \mathrm{~kg}$ in water \\
\hline & $100 \mathrm{~kg}$ in air \\
\hline Weights (ROV) & $\begin{array}{l}15 \mathrm{~kg} \text { in water } \\
40 \mathrm{~kg} \text { in air }\end{array}$ \\
\hline \multicolumn{2}{|l|}{ Materials } \\
\hline Sample rosette & $\begin{array}{l}\text { Polypropylene, polycarbonate, nylon, viton } \\
\text { rubber, titanium }\end{array}$ \\
\hline Rosette housing & $\begin{array}{l}\text { Nylon, Viton }{ }^{\mathbb{R}} \text { rubber, teflon, nickel alloy } \\
\text { (i.e. Hastelloy }{ }^{\mathbb{R}} \text { ), titanium }\end{array}$ \\
\hline Pumping system & 316 stainless steel, polycarbonate \\
\hline Pressure housing & Aluminum \\
\hline Mooring frame & 316 stainless steel \\
\hline ROV frame & Acetal copolymer \\
\hline Electrical & \\
\hline Disposable battery & $30 \mathrm{Ahr}$ alkaline pack \\
\hline Rechargeable battery & 10 Ahr NiMH pack \\
\hline ROV power & $36-28 \mathrm{~V}, 1 \mathrm{~A}$ max. \\
\hline Communication & RS-232 \\
\hline Controller & Onset Computer Corp. TattleTale 8 \\
\hline
\end{tabular}
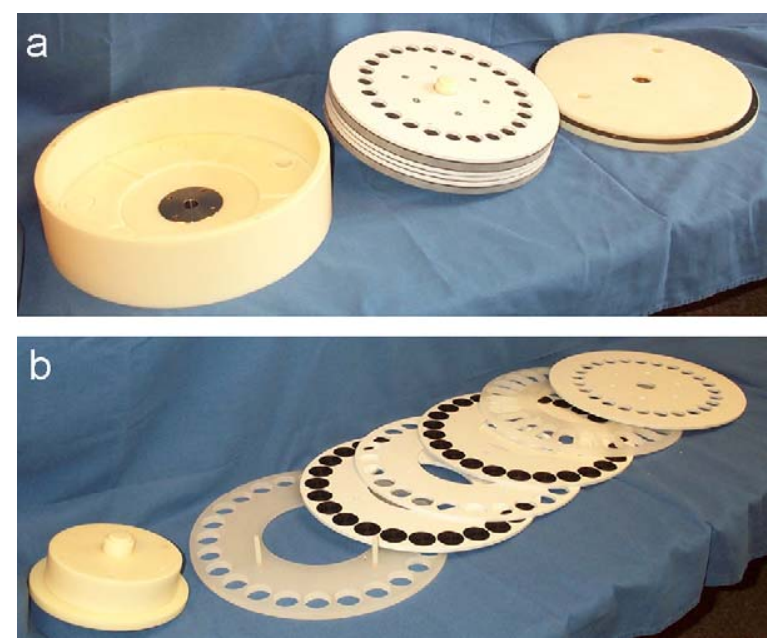

Fig. 3. (a) The SUPR sampling head consists of a filter rosette contained in a housing. (b) The filter rosette itself consists of a sequence of plates that support the filters and create the fluid flow paths and sample chambers; gaskets provide sealing between the plates, which are clamped together and connected to a central shaft with titanium fasteners.

and an outlet (Fig. 2). The closure at each inlet is created by a Viton ${ }^{\mathbb{R}}$ membrane, with slits, that acts as a simple check valve to positively retain the sample. Clamped between the inlet plate and the filter support plate is a baffle and gasket combination that serves as a mask, and creates 24 sample containments and lateral offsets. The lateral offsets provide for the optical windows above the samples set at a fixed radius from the filter rosette center
(Fig. 2b). Two filter stages are stacked together allowing the option of sub-sampling by size class. The filter rosette was fabricated from polypropylene and polycarbonate with Viton ${ }^{\circledR}$ gaskets and titanium shaft and fasteners.

The entire filter rosette is supported on 5 Teflon ${ }^{\circledR}$ face seals seated in the housing. Two of these face seals also serve to seal between the two housing outlets and the active sample flow paths. Sealing pressure is provided by a single titanium spring pressing down on the rotor shaft. To obtain a sample, water is drawn through each flow path sequentially by the pump, which is located downstream of the filtering head. The filtering head is interfaced with McLane Water Transfer System components: a 25 position actuator ( 24 sample ports and 1 dedicated purging port), a mechanical flow-meter, $5000 \mathrm{~m}$ ( $5500 \mathrm{~m}$ ROV version) pressure housing, a micro-controller (Onset Computer Corporation $\mathrm{TT} 8^{\mathrm{TM}}$ ), and an adaptation of McLane control software (Morrison et al., 2000). The software uses active feedback to reduce pumping speeds as the filters become loaded with sample and will stop collecting a sample when pump revolutions per minute drop below an operator-controlled threshold (pre-set for autonomous deployments but real-time for ROV deployments).

When configured for ROV operations the sampler is powered through the vehicle $(28-36 \mathrm{~V}$ at $1 \mathrm{~A} \max )$, is controlled in real time by serial communication (RS-232), and weighs $15 \mathrm{~kg}$ in water and $40 \mathrm{~kg}$ in air. When it is configured for autonomous operations, the SUPR sampler uses interchangeable $10 \mathrm{Ah} \mathrm{NiMH}$ rechargeable or $30 \mathrm{Ah}$ alkaline battery packs, and, with its dedicated mooring frame, weighs $60 \mathrm{~kg}$ in water and $100 \mathrm{~kg}$ in air. During ROV deployments individual sample volumes can be recorded with precision by simply monitoring the mechanical flow meter with one of the vehicle's video cameras. During autonomous deployments, a water volume-calibrated digital pump revolution counter is currently used to estimate individual sample volumes.

Based on laboratory pumping tests the current mechanical flow meter is both accurate and precise to within $10 \%$ of the actual volumes within the range of $10-100 \mathrm{~L}$. The accuracy of the digital pump revolution counter is comparable until the filters become heavily loaded with particulates at which point pump revolutions begin to underestimate the sample volumes. Therefore, for autonomous deployments the summed individual digital-counter estimates are compared with the total filtered volume per deployment as recorded by the mechanical flow meter. Individual sample-volume estimates are then adjusted by distributing the difference proportionally. A digital flow meter separate from the pump would solve this issue for autonomous deployments and we are testing options now. But our current focus is on ROV applications for which the mechanical flow meter is adequate.

\subsection{Future optical sensor integration}

The SUPR sampler is designed to host in situ optical analysis instruments in the future. The lateral offset in the flow path before the filter allows for this future application. Optical access to the sample is permitted above every 
sample port, allowing multiple techniques to be applied to the same sample, by moving the sample to specific locations, and to do so repeatedly after the sample has been collected. Techniques such as visible reflectance spectroscopy and image analysis using fluorescent stains are possible, but for hydrothermal mineral analysis we have focused on laser Raman spectroscopy (Brewer et al., 2004; White et al., 2005, 2006). For example, in pursuit of these goals, we have already developed methods and a database of Raman spectral characteristics that can be used to identify individual minerals in hydrothermal particle mixtures in situ and quantify the relative mineralogical composition of those mixtures (Breier et al., 2009).

\section{Methods}

\subsection{Sample collection}

The SUPR sampler was designed to systematically sample rising hydrothermal plumes during ROV deployments. The sampler can also be used for neutrally buoyant plume sampling either on a CTD water rosette to conduct transects of neutrally buoyant plumes or on fixed moorings for time-series sampling. Time series of up to 1 year are possible.

For rising plume sampling during a dedicated ROV dive, target vents are approached along the seafloor from off-site using the standard ROV navigation techniques (e.g., ultra-short baseline and long baseline navigation). The ROV then rises up through the water column adjacent to, rather than within, a rising buoyant plume. Samples are drawn from the buoyant plume into the SUPR sampler at increasing heights off bottom using an inlet "wand" held forward of the ROV. It is our current practice to collect sequential replicate samples above a focused vent at multiple elevations up through the neutrally buoyant plume. The first replicate pairs are collected just above the vent and subsequent samples are spaced at increasing intervals up into the uppermost region of the non-buoyant plume. The natural variability in particle concentration, due to turbulence, is reduced both by integration during the $10-30$ min required to collect each SUPR sample and through the collection of replicate samples that allow a first-order evaluation of temporal as well as spatial variability within these dynamic particle-laden environments. In the future, near-bottom and above plume background particulate samples will be included in the sampling plan and sample collection will be integrated with in situ sensor data: a light scattering sensor, Eh, dissolved $\mathrm{O}_{2}$, T, particle fluorescence and dissolved $\mathrm{Fe}$ and Mn. These measurements will allow us to develop threedimensional geochemical maps of the plume environment to better guide sampling and interpretation of the microbial community data.

For the samples collected during the trial deployments discussed in this paper, both polycarbonate membranes (GE Osmonics) and woven polyethersulfone (SUPOR ${ }^{\circledR}$ ) filters were used. The SUPOR ${ }^{\circledR}$ filters do not clog as rapidly and can filter more material but it is more difficult to remove that material from the filter for some subsequent microscopic analyses; in that regard the smooth polycarbonate membranes are superior. Upon recovery the sample rosette was brought into the lab and sheltered from air/dust with polyethylene sheeting. All samples were rinsed with distilled/deionized water, to remove sea salts and frozen until analysis. In the future, all sample handling will be done in a nitrogen purged glove box. Particulate samples will be rinsed upon recovery with filter-sterilized, neutral-pH buffered distilled/deionized water, to remove sea salts. Samples will be vacuum-sealed in nitrogen purged Ted Pella ${ }^{\circledR}$ containers and stored frozen until analysis. Filtered samples to be archived for microbial analysis will be handled in an aseptic manner and preserved consistent with standard protocols.

\subsection{Sample analysis}

We are using the EPR samples to investigate the finescale ( $\mu \mathrm{m}$ - and nm-range) mineralogical and biogeochemical composition of non-buoyant hydrothermal plume particles using i) synchrotron-based X-ray absorption spectromicroscopy now and ii) traditional thin-film XRD and elemental analysis in the future (Breier et al., 2008). The Scanning Transmission X-ray Microscopy (STXM) measurements presented here were performed at the Advanced Light Source beamline 11.0.2, Lawrence Berkeley National Laboratory, Berkeley, CA (Kilcoyne et al., 2003). This microscope uses a Fresnel zone plate lens to focus a monochromatic X-ray beam onto a sample to record transmission images. Material was resuspended from the polycarbonate filters and approximately $1 \mu \mathrm{L}$ of plume particle suspension was deposited onto a silicon nitride window (Silson Ltd.) for analysis. X-ray images were collected using a scintillator-photomultiplier detector assembly. Images recorded at energies below and at the Fe $2 \mathrm{p}$ and $\mathrm{C} 1 \mathrm{~s}$ absorption edges were converted into optical density images and used to derive elemental maps (optical density is equal to $\ln \left(I_{0} / I\right)$, where $I_{0}$ is the incident $\mathrm{X}$-ray intensity and $I$ is the transmitted intensity through the sample). All measurements were performed at ambient temperature and $\leq 1 \mathrm{~atm} \mathrm{He}$. The theoretical spatial and spectral resolutions of the beamline were $40 \mathrm{~nm}$ and $\pm 0.1 \mathrm{eV}$, respectively. The main $F e 2 \mathrm{p}_{3 / 2}$ resonance of the reference mineral ferrihydrite at $709.5 \mathrm{eV}$ was used for relative energy calibration at the Fe $2 p$ edges. The energy was calibrated at the $C 1$ s edge using the 3p Rydberg transitions of gaseous $\mathrm{CO}_{2}$ at 292.74 and $294.96 \mathrm{eV}$. All STXM data processing was carried out using the IDL (ITT Visual Information Solutions) software package aXis 2000 .

\section{First field deployment: East Pacific Rise, non-buoyant hydrothermal plume}

The SUPR sampler was successfully field tested during the LADDER 2007 cruise, led by L. Mullineaux, on a 3-day moored deployment in the non-buoyant hydrothermal plume above Tica vent at $9^{\circ} 50^{\prime} \mathrm{N}$ EPR in November 2007 (Fig. 4). The SUPR sampler was loaded with $37 \mathrm{~mm}$ 
a
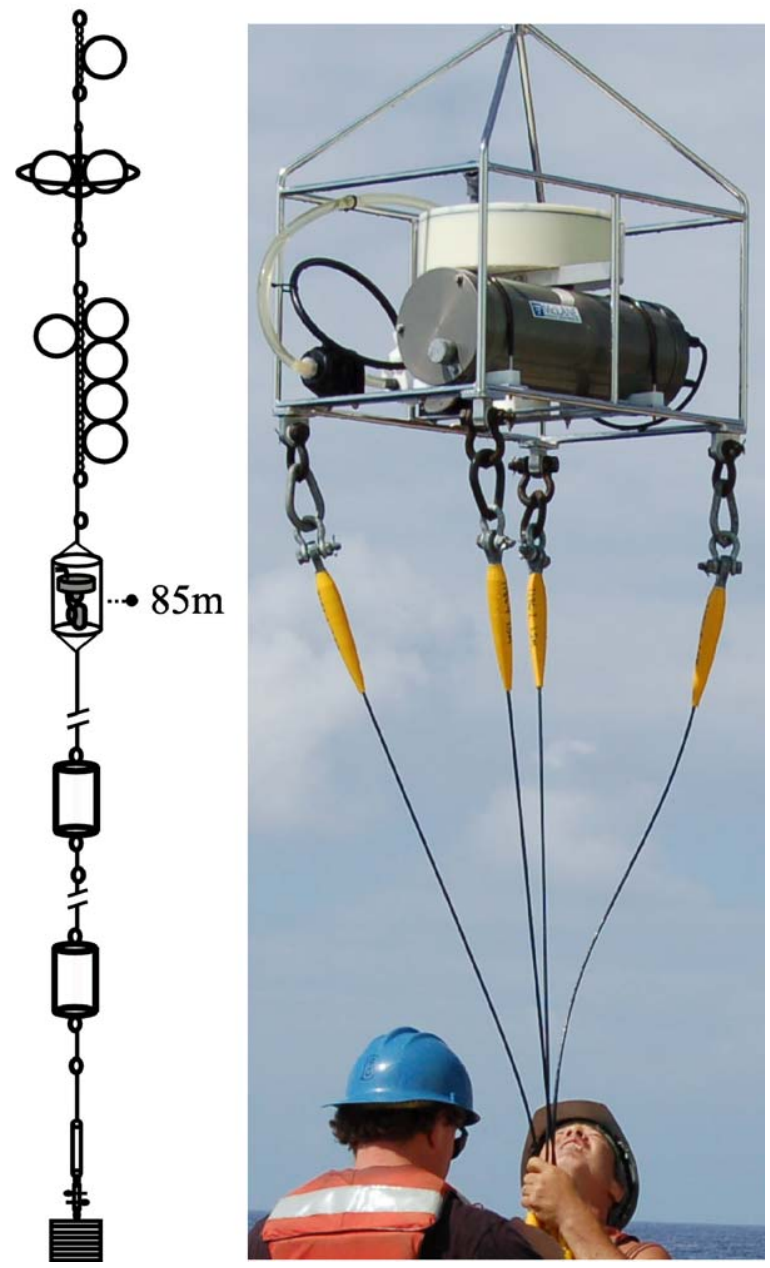

Fig. 4. (a) The SUPR sampler was first field tested during a 3-day mooring deployment in the neutrally buoyant hydrothermal plume $85 \mathrm{~m}$ above Tica Vent at $9^{\circ} 50^{\prime} \mathrm{N}$ East Pacific Rise in November 2007. (b) When configured for autonomous operations the SUPR sampler is powered with either $30 \mathrm{Ah}$ alkaline or $10 \mathrm{Ah} \mathrm{NiMH}$ battery packs.

diameter, $1 \mu \mathrm{m}$ pore size polycarbonate (GE Osmonics) filters and programmed to collect 24 samples. The sampler was positioned at $85 \mathrm{~m}$ above bottom, in the upper portion of the non-buoyant plume, on a mooring intended for larval sampling. The mooring was lowered from the surface with a transponder and released above the target site using long baseline navigation and the Alvin transponder network. The mooring was then positioned precisely by Alvin.

The sampler completed the deployment successfully, filtering up to $97 \mathrm{~L}$ per sample (Fig. 5, Table 2). During the 72-h deployment, the sampler was programmed to collect 24 evenly distributed time-series samples with the first starting at 0600 on 23 Nov. 2007 and the last starting at 0600 on 26 Nov. 2007. The sampler also implemented the adaptive sampling routine designed to: i) maximize sample volume during each sampling period, but ii) stop sampling before a filter ruptured. No filters ruptured, but there was large variability in the sample volumes (Table 2 ). This variability is at least partly due to temporal changes in particle concentration. Changes in particle size distribution or particle quality may also play a role, since the most densely loaded sample was also the one that filtered the highest volume (Fig. 5). However, the variability is also partly due to the sensitivity of the controller (as set by the coefficients of the proportional, integrative, and derivative feedback algorithm). Measurements of particle size distribution and concentrations from these natural samples will allow us to develop test solutions that can be used to more accurately adjust the control algorithm.

We recently completed a particle-by-particle, synchrotron-based X-ray absorption spectromicroscopic analysis of these samples. These measurements yield essential information about the elemental composition, mineralogy, and chemical speciation of major (e.g. Fe and C) and trace elements in the plume particles. These results indicate that a large proportion of plume particles are composed of Fe-bearing nanoparticles aggregated by a pervasive C-rich matrix (Fig. 6). This supports recent findings for descending plume particles collected in Tica vent EPR sediment traps (Toner et al., 2009). We have also used these samples to further test the limits of the in situ laser Raman spectroscopy techniques we have recently developed (Breier et al., 2009). These samples are now undergoing traditional thin-film XRD and elemental analysis.

\section{First ROV deployments: Mid-Atlantic Ridge, rising hydrothermal plumes}

Following the successful mooring deployment at $9^{\circ} 50^{\prime} \mathrm{N}$ EPR, the SUPR prototype was modified and optimized for use on an ROV. The ROV-version of the SUPR sampler weighs $7 \mathrm{~kg}$ in water and is compact enough to fit in either the swing-arm or rear-payload-bay positions of the ROV. The SUPR sampler was successfully deployed during multiple ROV Jason dives as part of the MAR July 2008 cruise led by A. Reysenbach. Deployments were completed at: 1) the ultramafic-hosted Rainbow vent site $\left(36^{\circ} 13^{\prime} \mathrm{N}, 33^{\circ} 54^{\prime} \mathrm{W}\right)$, and 2$)$ the basalt-hosted, Lucky Strike vent site $\left(37^{\circ} 17^{\prime} \mathrm{N}, 32^{\circ} 16^{\prime} \mathrm{W}\right)$. All deployments were successful, with the exception of one dive when a roll pin in the stepper drive mechanism broke; the pin was replaced immediately following that dive and successful operations continued. The deployment at F10 vent (Rainbow) was technically the most challenging because of a strong bottom current that caused the plume to rise at a $\sim 45^{\circ}$ angle. Despite this, Jason was able to hold lateral position while rising through the water column collecting six replicate pairs of samples at elevations up to $20 \mathrm{~m}$ above bottom (i.e. 1, 1, 2, 5, 10, and $20 \mathrm{~m}$ ) (Fig. 7). The particle-rich ascending plume could be visually identified directly from Jason's video feed at all elevations. Three replicate sample-pairs were also collected at $1 \mathrm{~m}$ above the orifice of the X3 vent at Rainbow. Similar deployments were conducted above Lucky Strike vents. Replicate samples were collected at $1,1,2,5,10$, and $20 \mathrm{~m}$ above 

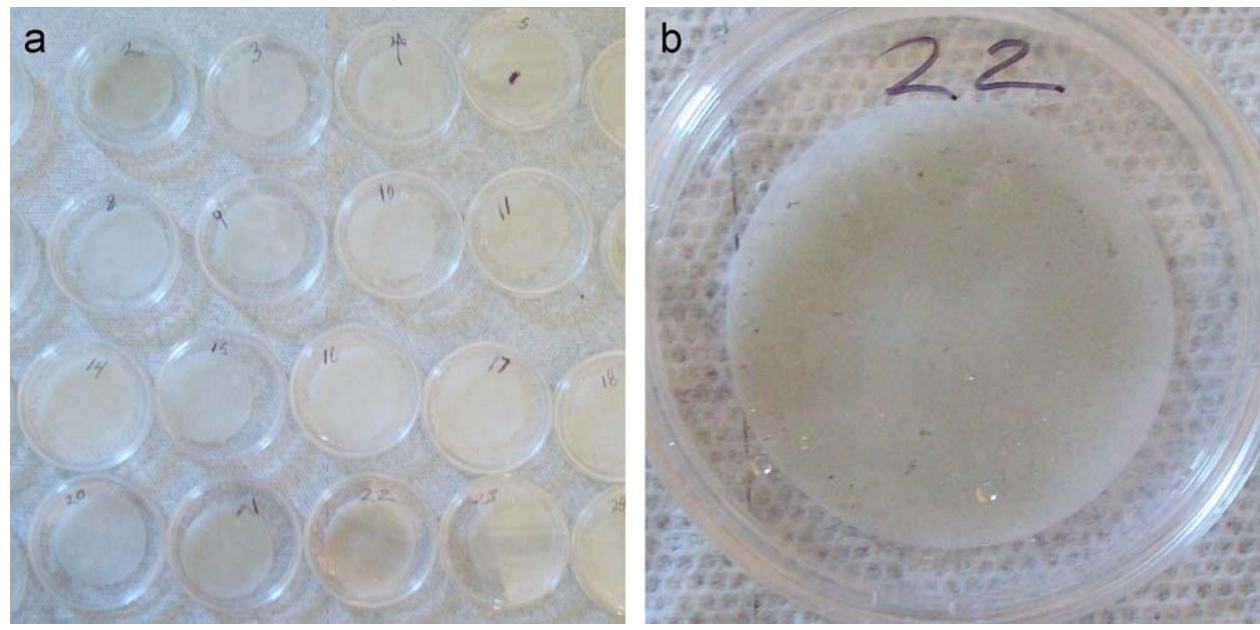

Fig. 5. (a) During the EPR mooring deployment the sampler successfully collected a 24 -sample time series. (b) The maximum volume filtered was $97 \mathrm{~L}$ (in this case using $37 \mathrm{~mm}$ diam., $1 \mu \mathrm{m}$ polycarbonate filters), achieving high particulate loading at the same time.

Table 2

$9^{\circ} 50^{\prime} \mathrm{N}$ East Pacific Rise neutrally buoyant plume particulate sample time series.

\begin{tabular}{|c|c|c|c|c|}
\hline \multicolumn{2}{|c|}{ Collection time } & \multicolumn{2}{|c|}{ Filters (pore size) } & \multirow[b]{2}{*}{ Volume (L) } \\
\hline Start & 23 Nov 07 & $1 \mu \mathrm{m}$ & $0.2 \mu \mathrm{m}$ & \\
\hline & 0600 & $\mathrm{x}$ & & 4.6 \\
\hline & 0907 & $\mathrm{x}$ & & 90.1 \\
\hline & 1215 & $\mathrm{x}$ & $\mathrm{x}$ & 0.2 \\
\hline & 1523 & $\mathrm{x}$ & & 23.9 \\
\hline & 1831 & $\mathrm{x}$ & & 42.9 \\
\hline & 2139 & $\mathrm{x}$ & & 18.7 \\
\hline & 0046 & $\mathrm{x}$ & & 4.6 \\
\hline & 0354 & $\mathrm{x}$ & & 2.2 \\
\hline & 0702 & $\mathrm{x}$ & & 7.2 \\
\hline & 1010 & $\mathrm{x}$ & & 2.3 \\
\hline & 1318 & $\mathrm{x}$ & & 22.8 \\
\hline & 1625 & $\mathrm{x}$ & $\mathrm{x}$ & 0.2 \\
\hline & 1933 & $\mathrm{x}$ & & 63.9 \\
\hline & 2241 & $\mathrm{x}$ & & 55.6 \\
\hline & 0149 & $\mathrm{x}$ & & 3.3 \\
\hline & 0457 & $\mathrm{x}$ & & 2.8 \\
\hline & 0805 & $\mathrm{x}$ & & 0.6 \\
\hline & 1112 & $\mathrm{x}$ & & 3.4 \\
\hline & 1420 & $\mathrm{x}$ & & 3.8 \\
\hline & 1728 & $\mathrm{x}$ & $\mathrm{x}$ & 0.2 \\
\hline & 2036 & $\mathrm{x}$ & & 55.0 \\
\hline & 2344 & $\mathrm{x}$ & & 97.0 \\
\hline & 0251 & $\mathrm{x}$ & & 44.1 \\
\hline & 0600 & $\mathrm{x}$ & & 11.7 \\
\hline End & 26 Nov 07 & & & \\
\hline
\end{tabular}

the orifice at the 2608 vent, and three replicate samplepairs were collected at $1 \mathrm{~m}$ above the orifice at Marker 4 vent.

For all dives, the SUPR sampler was loaded with $47 \mathrm{~mm}$ diameter, SUPOR ${ }^{\circledR}$ polyethersulfone membranes, in an alternating sequence of 0.8 and $0.2 \mu \mathrm{m}$ pore-size filters, which were collected as sequential duplicates. The $0.8-\mu \mathrm{m}$ filter samples collected closest to the vents were heavily loaded with particulates; samples collected from higher elevations were progressively less heavily loaded. Because of dive time constraints, sample volumes were typically limited to $5 \mathrm{~L}$. The $0.8-\mu \mathrm{m}$ filter sample volumes were limited only by time. The $0.2-\mu \mathrm{m}$ filters clogged rapidly after filtration of between 300 and $500 \mathrm{~mL}$. The $0.8-\mu \mathrm{m}$ filters will undergo the same geochemical analysis as the EPR particles. The $0.2-\mu \mathrm{m}$ filters have been archived for future microbial studies.

\section{Future directions}

Now that the basic sampler design and ROV sampling strategy have both completed sea trials successfully, we are planning a novel campaign of dedicated rising hydrothermal plume studies. To obtain a comprehensive suite of geochemical and microbial samples, including duplicate samples for a variety of analyses, we plan to expand the sampling capacity of the system in two ways. First we will add a second slaved SUPR sampling head so that 48 filters (24 replicate pairs of $47 \mathrm{~mm}$ diameter filters) can be collected per deployment. This will also provide an increased level of operational redundancy. Second, to increase filter volumes and obtain larger samples at the $0.2 \mu \mathrm{m}$ level, we will add a rack of 16 auxiliary $142 \mathrm{~mm}$ diameter filter holders that can be alternately connected to the SUPR pumping system using a manual valve actuated by the ROV manipulator.

In addition, because many particle characteristics are short lived, the SUPR sampler has been designed to be compatible with in situ optical techniques, such as laser Raman spectroscopy. Funding of the Ocean Observing Initiative (OOI) project is clear evidence that the future direction of oceanography lies in the development of sensors and sensor networks for observatories. The SUPR sampler is a prototype system for hosting in situ optical sensors to track compositional changes in suspended 

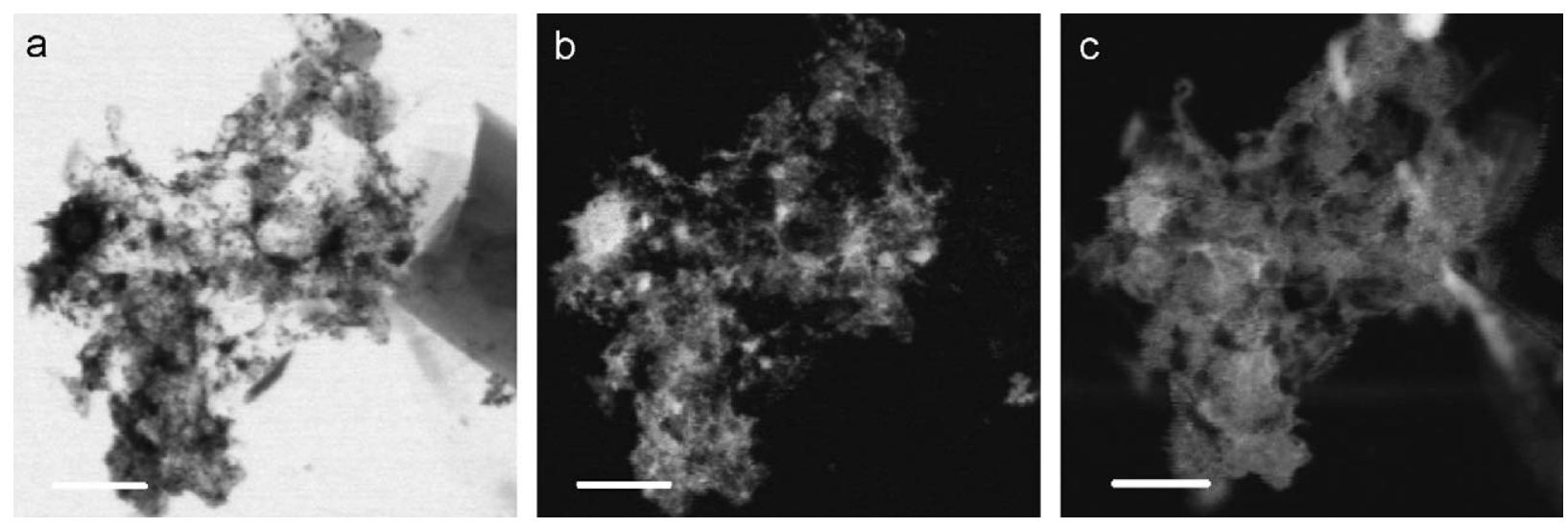

Fig. 6. Scanning Transmission X-ray Microscopy (STXM) images and elemental maps of an EPR Tica vent non-buoyant plume aggregate showing Fe-C association. (a) STXM image collected at the $\mathrm{Fe}_{2}$-edge $(709.5 \mathrm{eV}$ ). (b) Iron distribution map. (c) Carbon distribution map. Scale bar is $2 \mu \mathrm{m}$. Iron and carbon maps are in optical density units with values from 0 to 1.66 and 0 to 1.74 respectively.

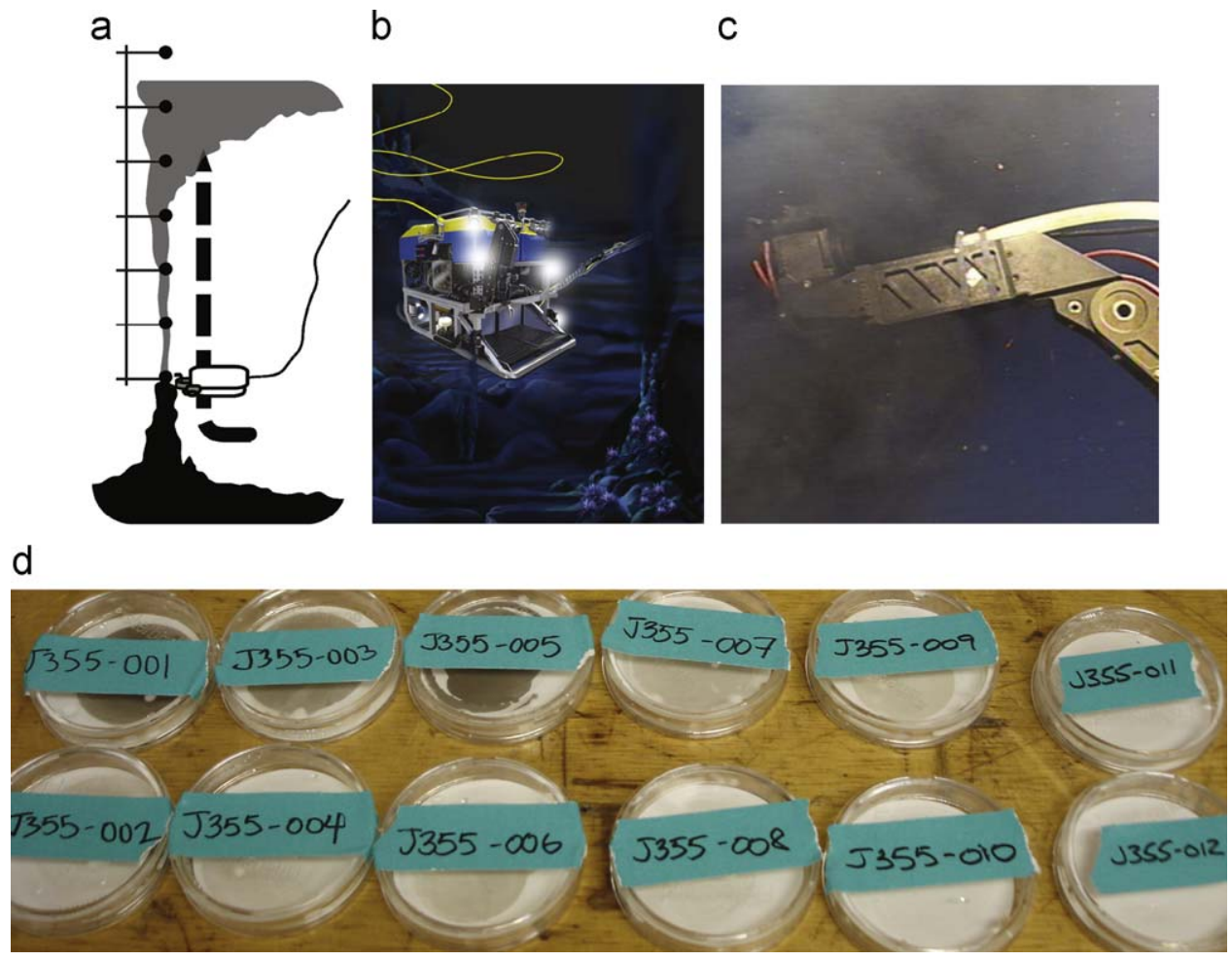

Fig. 7. (a) The SUPR sampler was successfully tested during deployments on ROV Jason in July 2008 proving our rising plume sampling strategy in the vent fields of the Mid-Atlantic Ridge. (b) Rising hydrothermal plumes were systematically sampled at increasing heights (a) by rising up through the water column adjacent to, rather than within, the rising buoyant plumes (b) (illustration by Oberlander) and, (c) using an inlet "wand" held forward of the ROV. (d) These $0.8 \mu \mathrm{m}$ (top row) and $0.2 \mu \mathrm{m}$ (bottom row) sets of paired samples were collected from the rising plume issuing from F10 vent at Rainbow at increasing plume elevations left to right $(1,1,2,5,10,20 \mathrm{~m})$.

particles. It can be deployed as a part of an ocean observatory to monitor long-term trends or capture changes in response to episodic (e.g., tectonic and volcanic) events. We are also working to develop a more comprehensive version of this system, that can perform both particulate and water sampling, specifically for autonomous underwater vehicle based studies of coupled physical and biogeochemical processes on the continental shelf. We see an increasing demand for this type of sampling capability - enabling both spatially resolved and temporally resolved sampling of suspended particles, including microbes, from a range of dynamic biogeochemical environments, in addition to hydrothermal systems. 


\section{Acknowledgments}

We would like to thank Lauren Mullineaux and the LADDER 2007 cruise crew and science party (NSF OCE-0424953), and Anna-Louise Reysenbach and the Mid-Atlantic Ridge 2008 cruise crew and science party (NSF-OCE-0728391, 0525907, 0549829) for allowing us to conduct trial deployments of the SUPR sampler. The Woods Hole Oceanographic Institution's Deep Ocean Exploration Institute funded construction of the SUPR sampler. Postdoctoral support for J.A.B. was through RIDGE 2000 (NSF OCE-0550331). During development, significant contributions were made by Mike Purcell and John Fetterman (WHOI), and Ken Doherty and Michael Mathewson, Ivory Engstrom, and Tim Shanahan (McLane Research Laboratories Inc.). The Advanced Light Source is supported by the Office of Science, Basic Energy Sciences, Division of Materials Science of the US Department of Energy (DE-AC02-05CH11231).

\section{References}

Anderson, R.F., Heinrich, D.H., Karl, K.T., 2003. Chemical Tracers of Particle Transport. Treatise on Geochemistry. Pergamon, Oxford, pp. 247-273.

Bach, W., Edwards, K.J., Hayes, J.M., Sievert, S., Huber, J.A., 2006. Energy in the dark: fuel for life in the deep ocean and beyond. EOS, Transactions, American Geophysical Union 87 (7), 73-78.

Bennett, S.A., Achterberg, E.P., Connelly, D.P., Statham, P.J., Fones, G.R., German, C.R., 2008. The distribution and stabilization of dissolved $\mathrm{Fe}$ in deep-sea hydrothermal plumes. Earth and Planetary Science Letters 270 (3-4), 157-167.

Breier, J.A., German, C.R., White, S.N., 2009. Mineral phase analysis of deep-sea hydrothermal particulates by a Raman spectroscopy expert algorithm: toward autonomous in situ experimentation and exploration, Geochemistry Geophysics Geosystems 10, Q05T05, doi:10.1029/ 2008GC002314.

Breier, J.A., Toner, B.M, Manganini, S.J., German, C.R., 2008. Hydrothermal plume particles deconstructed: evidence of biotic and abiotic interactions in particle formation at $9 \mathrm{~N}$ East Pacific Rise, EOS Transactions AGU, 89(53), Fall Meet. Suppl., Abstract B21A-0339.

Brewer, P.G., Malby, G., Pasteris, J.D., White, S.N., Peltzer, E.T., Wopenka, B., Freeman, J., Brown, M.O., 2004. Development of a laser Raman spectrometer for deep-ocean science. Deep-Sea Research I 51 739-753.

Butterfield, D.A., Roe, K.K., Lilley, M.D., Huber, J.A., Baross, J.A., Embley, R.W., Massoth, G.J., 2004. Mixing, reaction and microbial activity in sub-seafloor revealed by temporal and spatial variation in diffuse flow vents at Axial Volcano. In: Wilcock, W.S.D., DeLong, E.F., Kelley, D.S., Baross, J.A., Cary, S.C. (Eds.), The Subseafloor Biosphere at Mid-Ocean Ridges. American Geophysical Union, Washington, DC, pp. 269-289.

Cowen, J.P., Massoth, G.J., Baker, E.T., 1986. Bacterial scavenging of Mn and $\mathrm{Fe}$ in a mid- to far-field hydrothermal particle plume. Nature $322,169-171$

Cowen, J.P., Massoth, G.J., Feely, R.A., 1990. Scavenging rates of dissolved manganese in a hydrothermal vent plume. Deep-Sea Research 37, 1619-1637.

Cowen, J.P., German, C.R., 2003. Biogeochemical cycling in hydrothermal plumes. In: Halbach, P., Tunnicliffe, V., Hein, J. (Eds.), Energy and Mass Transfer in Marine Hydrothermal Systems. Dahlem University Press, Berlin, pp. 303-316.

Davis, R.E., Moyer, C.L., Curtis, A.C., Staudigel, H., Tebo, B.M., 2007. Bacterial diversity and spatial variability found in a Mn-Fe oxide encrusted microbial mat from the 5000 meter-deep hydrothermal vent 'Ula Nui, Hawaii. EOS, Transactions, American Geophysical Union 88 (52), Fall Meeting Supplement, Abstract B33A-0847.

De Angelis, M.A., Lilley, M.D., Baross, J.A., 1993. Methane oxidation in deep-sea hydrothermal plumes of the Endeavour segment of the Juan de Fuca Ridge. Deep-Sea Research I 40, 1169-1186.

Deming, J.W., Baross, J.A., 1993. Deep-sea smokers: Windows to a subsurface biosphere? Geochimica et Cosmochimica Acta 57, 3219-3230.
Dick, G.J., Lee, Y.E., Tebo, B.M., 2006. Manganese(II)-oxidizing Bacillus spores in Guaymas Basin hydrothermal sediments and plumes. Applied and Environmental Microbiology 72, 3184-3190.

Edmond, J.M., Campbell, A.C., Palmer, M.R., German, C.R., 1990 Geochemistry of hydrothermal fluids from the Mid-Atlantic Ridge: TAG and MARK 1990. EOS, Transactions, American Geophysical Union 71, 1650-1651.

Edmonds, H.N., German, C.R., 2004. Particle geochemistry in the Rainbow hydrothermal plume, Mid Atlantic Ridge. Geochimica et Cosmochimica Acta 68, 759-772.

Edwards, K.J., McCollom, T.M., Konishi, H., Busek, P.R., 2003. Seafloor bioalteration of sulfide minerals: results from in situ incubation studies. Geochimica Cosmochimica Acta 67, 2843-2856.

Elderfield, H., Schultz, A., 1996. Mid-ocean ridge hydrothermal fluxes and the chemical composition of the ocean. Annual Review of Earth and Planetary Sciences 24, 191-224.

Feely, R.A., Lewison, M., Massoth, G.J., Robert-Baldo, G., Lavelle, J.W., Byrne, R.H., Von Damm, K.L., Curl Jr., H.C., 1987. Composition and dissolution of black smoker particulates from active vents on the Juan de Fuca Ridge. Journal of Geophysical Research 92 (B11), 11,347-311,363.

Feely, R.A., Trefry, J.H., Massoth, G.J., Metz, S., 1991. A comparison of the scavenging of phosphorus and arsenic from seawater by hydrothermal iron oxyhydroxides in the Atlantic and Pacific Oceans. Deep Sea Research A 38, 617-623.

German, C.R., Von Damn, K.L., 2003. Hydrothermal Processes. Treatise on Geochemistry. Pergamon, Oxford, pp. 181-222.

Hardy, A.C., 1939. Ecological investigations with the Continuous Plankton Recorder: object, plan, and methods. Hull Bulletin of Marine Ecology 1, 1-57.

Huber, J.A., Butterfield, D.A., Baross, J.A., 2003. Bacterial diversity in a subseafloor habitat following a deep-sea volcanic eruption. FEMS Microbiology Ecology 43, 393-409.

Kadko, D., 1993. An assessment of the effect of chemical scavenging within submarine hydrothermal plumes upon ocean geochemistry. Earth and Planetary Science Letters 120, 361-374.

Kadko, D., Baross, J., Alt, J., 1995. The magnitude and global implications of hydrothermal flux. In: Humphris, S.E., Zierenberg, R.A., Mullineaux, L.S., Thomson, R.E. (Eds.), Seafloor Hydrothermal Systems: Physical, Chemical, Biological and Geological Interactions. American Geophysical Union, Washington, DC, pp. 446-456.

Kilcoyne, A.L.D., Tyliszczak, T., Steele, W.F., Fakra, S., Hitchcock, P., Franck, K., Anderson, E., Harteneck, B., Rightor, E.G., Mitchell, G.E., Hitchcock, A.P., Yang, L., Warwick, T., Ade, H., 2003. Interferometer-controlled scanning transmission X-ray microscopes at the Advanced Light Source. Journal of Synchrotron Radiation 10, 125-136.

Lilley, M.D., Feely, R.A., Trefry, J.H., 1995. Chemical and Biochemical transformations in hydrothermal plumes. In: Humphris, S.E., Zierenberg, R.A., Mullineaux, L.S., Thomson, R.E. (Eds.), Seafloor Hydrotherma Systems: Physical, Chemical, Biological and Geological Interactions. American Geophysical Union, Washington, DC, pp. 369-391.

Lupton, J.E., 1995. Hydrothermal plumes: near and far field. In: Humphris, S.E., Zierenberg, R.A., Mullineaux, L.S., Thomson, R.E (Eds.), Seafloor Hydrothermal Systems: Physical, Chemical, Biological and Geological Interactions. American Geophysical Union, Washington, DC, pp. 317-346.

McCollom, T.M., Shock, E.L., 1997. Geochemical constraints on chemolithoautotrophic metabolism by microorganisms in seafloor hydrothermal systems. Geochimica et Cosmochimica Acta 61, 4375-4391.

Metz, S., Trefry, J.H., 2000. Chemical and mineralogical influences on concentrations of trace metals in hydrothermal fluids. Geochimica et Cosmochimica Acta 64, 2267-2279.

Mitra, A., Elderfield, H., Greaves, M.J., 1994. Rare earth elements in submarine hydrothermal fluids and plumes from the Mid-Atlantic Ridge. Marine Chemistry 46, 217-235.

Morrison III, A.T., Billings, J.D., Doherty, K.W., 2000. The McLane WTS-LV: a large volume, high accuracy, oceanographic sampling pump. OCEANS 2000 MTS/IEEE Conference and Exhibition, pp. 847-852.

Mottl, M.J., Mcconachy, T.F., 1990. Chemical processes in buoyant hydrothermal plumes on the East Pacific Rise near $21^{\circ} \mathrm{N}$. Geochimica et Cosmochimica Acta 54, 1911-1927.

O’Brien, D., Carton, M., Eardly, D., Patching, J.W., 1998. In situ filtration and preliminary molecular analysis of microbial biomass from the Rainbow hydrothermal plume at $36^{\circ} 15^{\prime} \mathrm{N}$ on the Mid-Atlantic Ridge. Earth and Planetary Science Letters 157, 223-231.

Rendigs, R.R., Bothner, M.H., 2004. An operation manual for a time-series, storm activated suspended sediment sampler deployed in the coastal ocean: function, maintenance, and testing procedures. US Geological Survey, 56 
Rudnicki, M.D., Elderfield, H., 1993. A chemical model of the buoyant and neutrally buoyant plume above the TAG vent field, 26 degrees $\mathrm{N}$, Mid-Atlantic Ridge. Geochimica et Cosmochimica Acta 57, 2939-2957.

Sholkovitz, E., Allsup, G., Hosom, D., Purcell, M., 2001. An autonomous aerosol sampler/elemental analyzer designed for ocean buoys and remote land sites. Atmospheric Environment 35, 2969-2975.

Straube, W.L., Deming, J.W., Somerville, C.C., Colwell, R.R., Baross, J.A., 1990. Particulate DNA in smoker fluids: evidence for existence of microbial populations in hot hydrothermal systems. Applied and Environmental Microbiology 56, 1440-1447.

Taylor, C.D., Doherty, K.W., Molyneaux, S.J., III, A.T.M., Billings, J.D. Engstrom, I.B., Pfitsch, D.W., Honjo, S., 2006. Autnomous Microbial Sampler (AMS), a device for the uncontaminated collection of multiple microbial samples from submarine hydrothermal vents and other aquatic environments. Deep-Sea Research I 53 , 894-916.

Toner, B.M., Fakra, S.C., Manganini, S.J., Santelli, C.M., Marcus, M.A., Moffett, J.W., Rouxel, O., German, C.R., Edwards, K.J., 2009. Preservation of iron(II) by carbon-rich matrices in a hydrothermal plume. Nature Geoscience 2, 197-201.

White, S.N., Kirkwood, W.J., Sherman, A.D., Brown, M.O., Henthorn, R., Salamy, K.A., Walz, P.M., Peltzer, E.T., Brewer, P.G., 2005. Development and deployment of a precision underwater positioning system for in situ laser Raman spectroscopy in the deep ocean. Deep-Sea Research I 52, 2376-2389.

White, S.N., Dunk, R.M., Brewer, P.G., Peltzer, E.T., Freeman, J.J., 2006. In situ Raman analyses of deep-sea hydrothermal and cold seep systems (Gorda Ridge \& Hydrate Ridge). Geochemical, Geophysical, and Geosystems 7, Q05023. 